\title{
Assessment of vitamin D, calcium, inorganic phosphate, alkaline phosphatase and parathormone in juvenile idiopathic arthritis patients
}

\author{
SUFIA KHATUN SUMI ${ }^{1}$, SHAHANA A RAHMAN ${ }^{2}$, MOHAMMAD IMNUL ISLAM ${ }^{3}$, \\ MOHAMMAD MAHBUBUL ISLAM ${ }^{3}$, MANIK KUMAR TALUKDER ${ }^{3}$
}

\begin{abstract}
Background: Decrease in bone mass in JIA patients is multifactorial. By assessing the level of vitamin $D$ and other associated parameters we can identify the deficiency earlier and can predict the risk of osteoporotic bone fracture \& give appropriate supplements.
\end{abstract}

Objective: To determine the status of serum $25(\mathrm{OH}) \mathrm{D}$, calcium, inorganic phosphate, alkaline phosphatase and parathormone in patients with JIA.

Materials and methods: It was a cross sectional study. Thirty newly diagnosed cases of JIA attending the pediatric rheumatology clinic of Bangabandhu Sheikh Mujib Medical University (BSMMU), Dhaka from October 2015 to September 2016 were included. Thirty age and sex matched control were also selected. Serum $25(\mathrm{OH}) \mathrm{D}$, calcium, inorganic phosphate, alkaline phosphatase \& parathormone were assesed in both cases and controls.

Results: Hypovitaminosis D was present in $60 \%$ of JIA and $33 \%$ of controls. In JIA group the mean level of all biochemical parameters were significantly lower than control group except serum $25(\mathrm{OH}) \mathrm{D}$. Level of calcium, inorganic phosphate and alkaline phosphatase was decreased with the decrease of $25(\mathrm{OH}) \mathrm{D}$ levels and there was no change of parathyroid hormone level.

Conclusion: More than half of JIA patients had hypovitaminosis $D$. There was positive relationship between 25(OH)D level and other biochemical parameters except PTH.

Keywords: Juvenile Idiopathic Arthritis(JIA), Vitamin D, Serum Calcium, Parathyroid Hormone.

\section{Introduction}

Juvenile idiopathic arthritis (JIA) is one of the most common chronic illnesses of childhood. ${ }^{1}$ There are multifactorial causes of low bone mass in JIA patients.

1. Pediatrician, National Institute of Neurosciences \& Hospital, Dhaka.

2. Professor, Department of Paediatrics, Bangabandhu Sheikh Mujib Medical University (BSMMU), Dhaka.

3. Associate Professor, Department of Paediatrics, Bangabandhu Sheikh Mujib Medical University (BSMMU), Dhaka.

Correspondence: Dr. Sufia Khatun Sumi, Pediatrician, National Institute of Neurosciences \& Hospital, Dhaka. Cell phone:- +8801819118790, Email:drsufiakhatunsumi@gmail.com

Received: 21/07/18

Accepted: 6/01/2019
Among them acute inflammatory disease, decreased physical activity, nutritional insufficiency, inadequate sun exposure and glucocorticoid excess are important. ${ }^{2}$ In addition, new information suggesting a role of vitamin $D$ in immune modulation has led to a surge of interest among the rheumatologists. Vitamin $D$ might be an environmental factor that normally participates in the control of self-tolerance \&decrease in the Th1-driven autoimmune response. ${ }^{3}$ In spite of limited epidemiologic data; it appears that many children with rheumatic conditions are at risk of vitamin $\mathrm{D}$ deficiency. ${ }^{4,5}$ 
Bone is a special form of connective tissue with a collagen framework impregnated with calcium \& phosphate salts particularly hydroxyapatites. It is involved in overall calcium \& phosphate homeostasis. There are two major hormones regulating calcium and phosphate homeostasis: active form of vitamin $\mathrm{D}$ and parathyroid hormone ${ }^{6}$ Vitamin $\mathrm{D}$ elevates plasma calcium and phosphate by increasing absorption in the intestine, calcium mobilization in bone and calcium reabsorption in the kidney. ${ }^{7,8}$ Vitamin $\mathrm{D}$ deficiency is associated with impaired intestinal calcium absorption resulting in compensatory hyperparathyroidism, increased bone resorption, and decreased bone integrity. Parathormone (PTH) causes elevation of calcium but decreases phosphate by increasing its renal excretion. Serum alkaline phosphatase is also elevated during bone turnover. These biochemical parameters of bone turnover are indirect indices of skeletal metabolism. ${ }^{6}$

Loss of bone mass leaves thebone more susceptible to breakage and the incidence of fracture is increased. So children with JIA are a risk for osteopenia and osteoporosis which may result in vertebral compression and fractures of long bones are increased..$^{9,10} \mathrm{~A}$ pilot study done in Bangladesh found low bone mineral density (BMD) by DEXA scan in JIA patients. ${ }^{11}$ However, to the best of our knowledge, no data available of Bangladeshi children regarding vitamin $\mathrm{D}$ and other associated parameters in JIA patients. The aim of this study was to estimate the concentrations of 25-hydroxyvitamin $\mathrm{D}[25(\mathrm{OH}) \mathrm{D}]$, calcium, inorganic phosphate, alkaline phosphatase and parathormone (PTH) in patients with JIA and to compare them with control. We also assessed the relationship of above parameters with vitamin D level in JIA patients.

\section{Materials and methods:}

Thirty newly diagnosed children with JIA attending the pediatric rheumatology clinic, Bangabandhu Sheikh Mujib Medical University (BSMMU), Dhaka, Bangladesh from October 2015 to September 2016 were included in this cross sectional study. Patients were excluded if they had either an additional chronic disease (endocrine, neurological, cardiac, renal, liver disease, rickets or bone disease) that could affect bone metabolism, or were receiving treatment including corticosteroids and/or calcium and vitamin $D$ supplementation. Thirty age and sex matched controls were selected from the outpatient department who attended the hospital because of acute illness other than bone disease, and who were not taking supplements of vitamin $D$ or calcium. Ethical clearance was taken from the Institutional Review Board (IRB) of BSMMU. Informed written consent was obtained from all the participants or parents. Information were obtained from their medical records, which included current age (years), gender, duration of disease (months) and disease sub-type according to the ILAR classification criteria.Blood samples were drawn for the following laboratory tests: serum $25(\mathrm{OH}) \mathrm{D}$, calcium, inorganic phosphate, alkaline phosphatase \& parathormone. Estimation of serum $25(\mathrm{OH}) \mathrm{D}$ was done by Chemiluminescence microparticle immune assay (CMIA) technique using the analyzer Architect Abott, Ci 4100, USA 2012. Serum calcium, inorganic phosphate, alkaline phosphatase and parathyroid hormone were estimated by standard method practiced by Department of Biochemistry, BSMMU. Depending on their $25(\mathrm{OH}) \mathrm{D}$ level, patients were classified into 2 categories: hypovitaminosis $D(<32 \mathrm{ng} / \mathrm{ml}$ includes Vitamin $D$ deficiency $<20 \mathrm{ng} / \mathrm{mland}$ VitaminD insufficiency $20-32 \mathrm{ng} / \mathrm{ml}$ and Vitamin D sufficiency $(>32 \mathrm{ng} / \mathrm{ml})^{\cdot 12}$

All the statistical calculations were done using the statistical software SPSS 21.0. The Chi-square test, the unpaired student t-test, Pearson correlation test and scatter diagram had been applied to evaluate the association between the variables when indicated. Here $p$-value of less than 0.05 was considered as significant at a $95 \%$ confidence interval $(95 \% \mathrm{Cl})$ for the correlation.

\section{Results:}

The mean age of the JIA patients at diagnosis was 9.48 year (age range: 1.33-14 year). Sixteen were male $(53 \%)$ and 14 were female $(47 \%)$. The mean age of controls was 9.63 year (age range: 1.2-14 year) and among them 16 were male and 14 were female. Table-I shows that in JIA group the mean level of serum $25(\mathrm{OH}) \mathrm{D}$, calcium, inorganic phosphate, alkaline phosphatase (ALP) and parathyroid hormone $(\mathrm{PTH})$ were $26.86 \pm 10.97$, 
Table I

Comparison of level of serum 25(OH)D, inorganic phosphate, alkaline phosphatase and parathyroid hormone in JIA and control group $(n=30+15)$

\begin{tabular}{lccc}
\hline & $\begin{array}{l}\text { JIA }(\mathrm{n}=30) \\
\text { Mean } \pm \text { SD }\end{array}$ & $\begin{array}{c}\text { Control }(\mathrm{n}=15) \\
\text { Mean } \pm \text { SD }\end{array}$ & *p-value \\
\hline S. 25(OH)D (ng/ml) & $26.86 \pm 10.97$ & $31.47 \pm 6.11$ & 0.135 \\
S. Calcium (mg/dl) & $7.92 \pm 1.54$ & $9.24 \pm 0.69$ & 0.003 \\
S. inorganic phosphate $(\mathrm{mg} / \mathrm{dl})$ & $4.01 \pm 1.10$ & $5.23 \pm 0.66$ & 0.0001 \\
S. alkaline hosphatase (U/L) & $131.50 \pm 51.72$ & $206.73 \pm 41.6$ & 0.0001 \\
S. PTH $(\mathrm{pg} / \mathrm{ml})$ & $30.46 \pm 16.77$ & $76.36 \pm 33.07$ & 0.0001 \\
\hline
\end{tabular}

*unpaired student t-test

Table II

Status of 25(OH)D among JIA and Control group $(n=30+15)$

\begin{tabular}{lccccc}
\hline 25(OH) D level & \multicolumn{2}{c}{ JIA group } & \multicolumn{2}{c}{ Control group } & *p-value \\
& $\mathrm{N}$ & Mean \pm SD & $\mathrm{n}$ & Mean \pm SD & \\
\hline Hypovitaminosis D $(<32 \mathrm{ng} / \mathrm{ml})$ & 18 & $19.15 \pm 6.05$ & 5 & $26.44 \pm 3.69$ & 0.007 \\
Sufficient level of D $(>32 \mathrm{ng} / \mathrm{ml})$ & 12 & $38.31 \pm 4.5$ & 10 & $37.11 \pm 4.3$ & 0.55 \\
\hline
\end{tabular}

*unpaired student t-test

$7.92 \pm 1.54, \quad 4.01 \pm 1.10, \quad 131.50 \pm 51.72$ and $30.46 \pm 16.77$ respectively all of which were much lower than control group. All the levels were statistically significant except serum $25(\mathrm{OH})$ D levels. In the JIA group, $37 \%$ had $25(\mathrm{OH}) \mathrm{D}$ deficiency, $23 \%$ had insufficient level and $40 \%$ had sufficient level of 25(OH)D. Among control group, none had deficiency, $33 \%$ had insufficiency and $67 \%$ had sufficient level of 25(OH)D. Hypovitaminosis D (deficiency+ insufficiency) was found in $60 \%$ of JIA patients. (Fig. 1). Table-Il shows that there is significant difference in terms of mean value of vitamin $D$ level in JIA and control group for the cases of hypovitaminosis $\mathrm{D}$. The Correlation among serum calcium, inorganic phosphate, alkaline phosphatase, PTH level and 25(OH)D level was done $(r=-0.37, p=0.04)$ which is shown in scatter diagram (Fig.2), indicates that that there is statistically significant positive relationship with 25(OH)D and serum calcium, serum inorganic phosphate and alkaline phosphatase. It indicates that the level of calcium, inorganic phosphate and alkaline phosphatase are decreaesed with the decrease of the level of 25(OH)D. This figure also showed that $\mathrm{PTH}$ had no significant relationship with the level of $25(\mathrm{OH}) \mathrm{D}$.

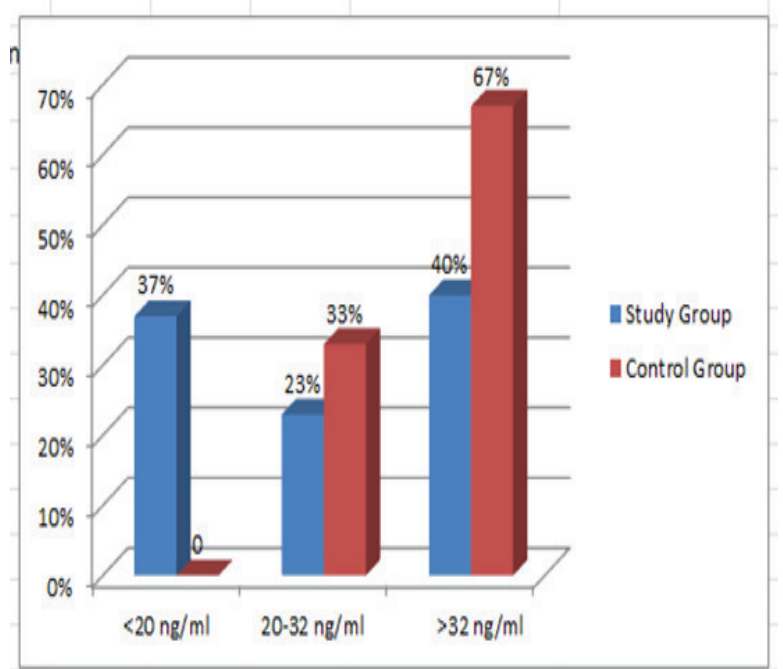

Fig.-1: Bar Diagram showing serum 25(OH)D level in the Study and Control Group 


\section{এ গ্রাফগুলি ভাল করে দেখতে হবে}

BANGLADESH J CHILD HEALTH 2019; VOL 43 (3) : 148
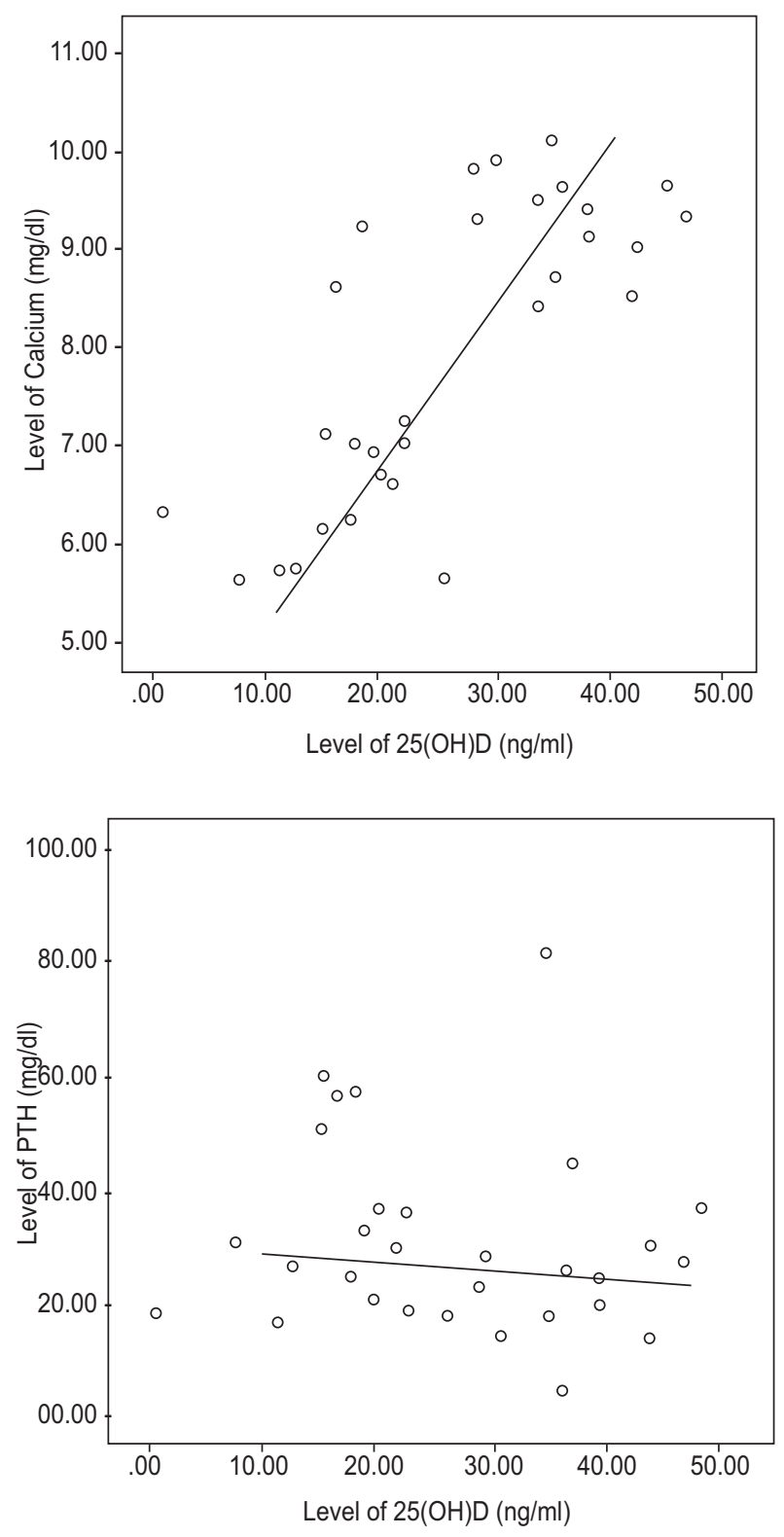

Assessment of vitamin $\mathrm{D}$, calcium, inorganic phosphate
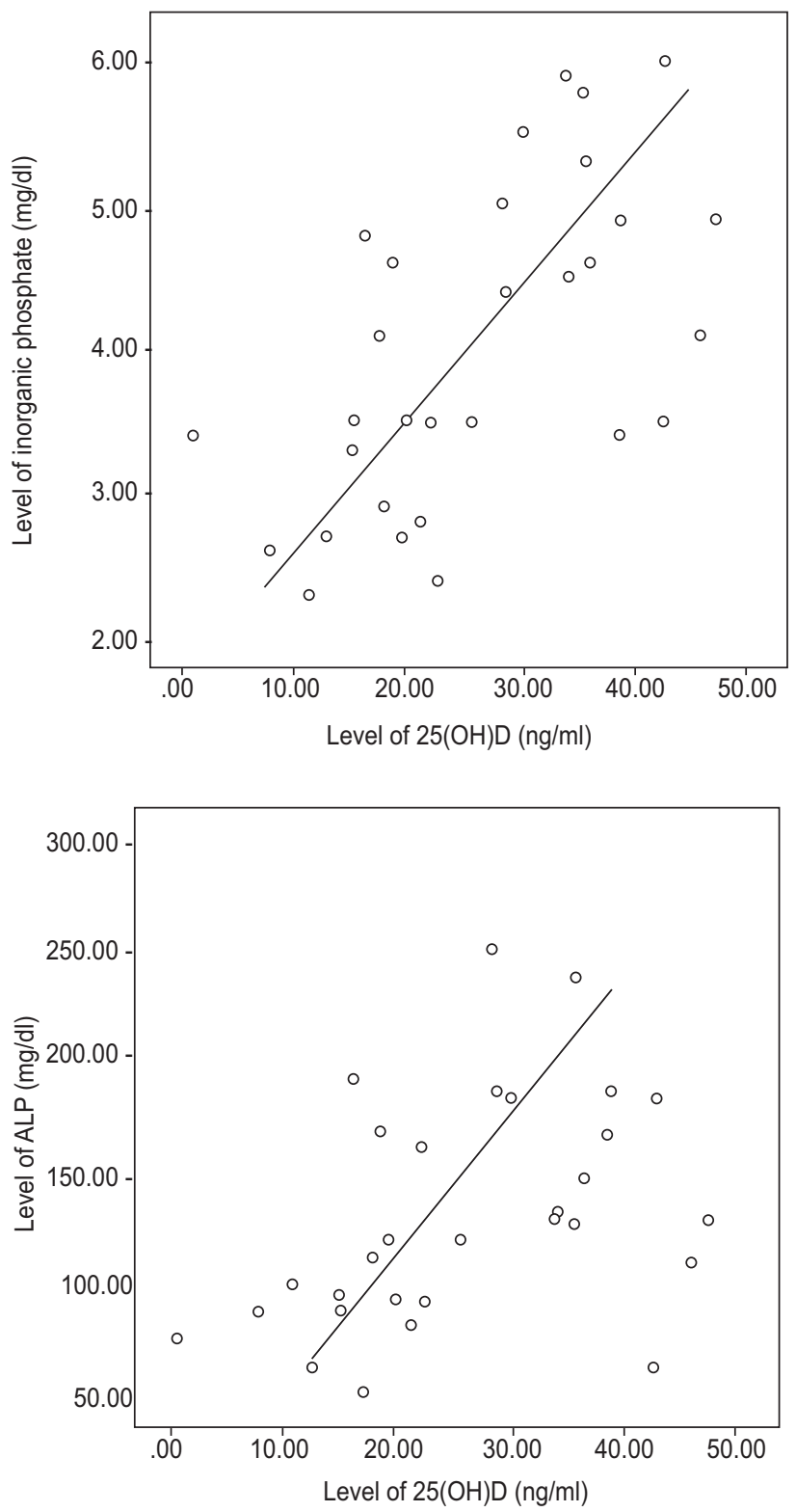

Fig-2: Scatter diagram showing relationship among the level of $25(\mathrm{OH}) \mathrm{D}$ and calcium, inorganic phosphate, parathyroid Hormone and alkaline phosphatase.

\section{Discussion}

As many as one billion people worldwide suffer from low level of vitamin $D .^{7,13,14}$ In recent years, information suggesting vitamin $D$ deficiency as a possible risk factor for autoimmune diseases has led to an interest among rheumatologists. ${ }^{15}$ In the present study, although the mean level of $25(\mathrm{OH}) \mathrm{D}$ was not significantly different between JIA and control group (Table I), when the groups were subdivided in hypovitaminosis $D$ level and sufficient level of vitamin $D$ (Table II), it was found that mean level of vitamin $D$ among hypovitaminosis group was significantly lower in JIA patients than that of control group. It could be due to the fact that there were more JIA patients with very low levels of vitamin $D$ than the control group. Low vitamin $D$ levels were found in both patients with JIA and controls but it was more so among the patients. A total of $18(60 \%)$ JIA patients were found to have hypovitaminosis $D$ (Table II), a result similar to that reported from Morocco. ${ }^{16}$ This finding is consistent with the findings carried out on American JIA patients and Brazilian polyarticular JIA patients, ${ }^{4-5}$ 
although these studies did not report any significant difference between JIA patients and controls in spite of having high frequency of $25(\mathrm{OH}) \mathrm{D}$ deficiency and insufficiency. Potential explanations for the high frequency of deficiency/ insufficiency in our study as well as other studies may be due to the dietary insufficiency, lifestyle changes and seasonal variation.

The level of serum calcium, inorganic phosphate, alkaline phosphatase and parathyroid hormone (PTH) in JIA group were also significantly lower than control group (Table I) though the levels were within normal limit. These findings are consistent with the research carried on JIA patients and healthy control by Hillman et al. and Munekata et al. ${ }^{4,5}$

Lower level of serum calcium in JIA group may be due to multiple factors including low level of vitamin D causing decreased absorption of calcium, less food intake due to anorexia of chronic illness. This finding may also be explained by the reduced capacity for mineral absorption described in children with arthritis $^{17}$. A study in animal models with induced arthritis found a reduction in $1,25(\mathrm{OH}) \mathrm{D}$ receptors, with a consequent reduction in calcium absorption. ${ }^{18}$ This could be another explanation for low level of calcium. However, it was expected that calcium level would be normalized in JIA group as a part of compensatory mechanism by increased PTH level, but it was not found so. In the present study there were normal level of parathormone in spite of low 25(OH)D and calcium in the JIA group. Munekata et al. also reported normal level of mean PTH in theirstudy. ${ }^{5}$ Our findings were also very much similar to study done by Thacher and Clare. ${ }^{19}$ They also found that parathyroid hormone level was normal in spite of low 25(OH)D. Hillman et al also found normal parathyroid hormone level in spite of significantly lower serum calcium concentration and concluded that PTH level may be inappropriately normal for the decreased serum calcium concentration in children with JIA. ${ }^{4}$ In this regard Holick ${ }^{7}$ added that if associated hypomagnesaemia is present it may blunt the response of PTH that means parathyroid hormone levels are often normal when $25(\mathrm{OH}) \mathrm{D}$ level fall below 20 ng per milliliter. ${ }^{11}$ In the present study serum magnesium level was not measured. So we cannot definitely draw any conclusion. But JIA patients are usually nutritionally compromised ${ }^{20}$ and thereby may have associated hypomagnesaemia. In addition patient with low turnover bone disease may also have the lowest concentration of PTH. ${ }^{4}$ So, it is evident that though inverse association between PTH and $25(\mathrm{OH}) \mathrm{D}$ were observed in adult patients with rheumatoid arthritis in the research done by Kumar et al; Gordon et al. and Gordon et al ${ }^{20-22}$ but this association has not been frequently observed in JIA patients (Fig.-2).

In our study, we found elevated mean PTH level in the control group but not in JIA group. This finding may be explained by the fact that a number of control group also showed insufficient level of vitamin D. As vitamin $D$ deficiency progresses it causes calcium deficiency and thereby the parathyroid glands are maximally stimulated, causing secondary hyperparathyroidism. ${ }^{7}$ Normal level of inorganic phosphate in JIA group was found in the present study though it was significantly lower in comparison to control group. This may be explained by the fact that there was no PTH induced lowering of renal threshold followed by phosphaturiain spite of decreased serum calcium level.

In this study relatively lower level of alkaline phosphatase was found in JIA patients in comparison to control group. This finding is different from other common metabolic bone disease like rickets and bony dysplasia in children, where alkaline phosphatase level is increased due to increased osteoblastic activity for bone formation. Reduced bone formation occurs in JIA patients which are also supported by the study done by Hillman et al. ${ }^{4}$ They also found decreased bone mineral content in his study and concluded that decreased mineralization occurs in JIA patients which is related to low bone turnover. ${ }^{4}$ This finding is also similar to the study done by Maresova who explained that proinflammatory cytokines and TNF- $\alpha$ significantly elevates bone resorption and attenuates osteoblastogenesis and bone formation in JIA patients. ${ }^{23}$

The present study found that $37 \%$ of JIA patients had $25(\mathrm{OH}) \mathrm{D}$ deficiency and $23 \%$ of them had $25(\mathrm{OH}) \mathrm{D}$ insufficiency. A study done on forty Moroccan children with JIA showed that $45 \%$ had $25(\mathrm{OH}) \mathrm{D}$ deficiency and $30 \%$ had insufficiency. This slight lower percentage of our patients may be explained by the fact that most of the patients (57.5\%) of Bouaddi et al. study were receiving corticosteroids along with other treatment. ${ }^{16}$ It is to be mentioned here that our study did not include any patients receiving steroids. 


\section{Conclusion}

Significant hypovitaminosis D was present among more than half of JIA patients. Positive relationship was found between 25(OH)D and other biochemical parameters including serum calcium, inorganic phosphate and alkaline phosphatase and no significant relationship with PTH level in JIA patients.

\section{Limitations}

It was a single centered study and sample size was small. Dietary intake of vitamin $D$, sunlight, nutritional status, disease activity was not studied.

\section{Declarations}

Ethics approval and consent to participate:The research proposal titled "Assessment of serum concentrations of vitamin $D$, calcium, inorganic phosphate, alkaline phosphatase and parathormone in juvenile idiopathic arthritis patients" has been reviewed and approved by the Institutional Review Board of Bangabandhu Sheikh Mujib Medical Univertsity, Dhaka. Consent was taken in the consent form from the participants and /or their parents.

Consent for publication: Consent for publication was taken from the respective authority.

Availability of data and materials: The data generated during the study are not publicly available.

Competing interest: There is no competing interest.

Funding: This was a self-funded study.

Authors'contributions: Sufia Khatun Sumi was involved in the conception, design, drafting, data collection, data analysis and report writing. Shahana A Rahman was involved in conception, designing of the study, collection and supervision of data collection, preparation of manuscript and editing the research report. Mohammed Mahbubul Islam, Mohammad Imnul Islam and Manik Kumar Talukder were involved in data collection, compilation and supervision.

Acknowledgements: We would like to thank our patients who participated in this study and their parents. We would also like to thank our paediatricians who facilitated the study.

\section{References:}

1. EvelineYWu, Bryan RA, Rabinovich, CE. Juvenile Idiopathic Arthritis. In: Kliegman RM, Stanton BF, Schor NF, Geme JWS, Behrman RE, editors. Nelson Textbook of Paediatrics. $20^{\text {th }}$ edition.Saunder; Philadelphia: 2016; 1160-70.

2. Burnham JM, Shults J, Dunber SE, Sembhi H, Zemel BS, Leonard MB. Bone Density, Structure, and Strength in Juvenile Idiopathic Arthritis: Importance of Disease Severity and Muscle Deficits. Arthritis Rheum 2008; 58: 2518-27.

3. Petty RE, LaxerRM,Wedderburn LR. Juvenile Idiopathic Arthritis. In: Petty RE,Laxer RM, Lindsley CB,Wedderburn LR. Editors. Textbookof Pediatric Rheumatology. $7^{\text {th }}$ edition. Elsevier Saunders; Philadelphia: 2016. 188-03.

4. Hillman LS, Cassidy JT, Johnson L, Lee D, Allen $\mathrm{SH}$. Vitamin D Metabolism and Bone Mineralization in Children with Juvenile Rheumatoid Arthritis. J Pediatr 1994; 124: $910-16$.

5. Munekata RV, TerreriMTRA, Peracchi OAB, Len C, Lazaretti-Castro M, Sarni ROS. Hilari, MOE. Serum 25-hydroxyvitamin D and Biochemical Markers of Bone Metabolism in Patients with Juvenile Idiopathic Arthritis. Brazilian Journal of Medical and Biological Research 2013; 46: 98-102.

6. Barrett, KE, Barman, SM, Boitano, S \& Brooks, HL2012, Ganong's Review of Medical Physiology, Lanze, pp. 377-90.

7. Holick, MF. Vitamin D deficiency. N Engl J Med 2007; 357: 266-81.

8. DeLuca, H.F. Overview of general physiologic features and functions of vitamin D. Am J ClinNutr, 2004; 80: 1689S-96S.

9. Rolando C, Leanne W. The Impact of Rheumatic Deseases and Their Treatment on Bone Strenth Develoment in Childhood. In: Petty RE, Laxer RM, Lindsley CB, Wedderburn LR. Editors. Textbook of Pediatric Rheumatology. 7th edition. Elsevier Saunders; Philadelphia: 2016. pp. 693-05.

10. Kati P. Markula-Patjas, Helena L. Valta, Liisa I. Kerttula, Irma H. Soini, Viasa EA, Honkanen, Sanna-Maria Toiviainen-Salo, Makiti OM. Prevalence of Vertebral Compression Fractures and Associated Factors in Children and Adoloscents with Severe Juvenile Idiopathic 
Arthritis. The journal of Rheumatology 2012; 39: 365-73.

11. Islam MF, Islam MM, Talukdar MK, Rahman SA. Bone Mineral Density in Children with Juvenile Idiopathic Arthritis: A Hospital Based Study. Bangladesh Journal of Child Health 2013; 37 : 18-21.

12. Grant WB, Holick MF. Benefits and Requirements ofVitamin D for Optimum Health. Alternative Medicine Review 2005; 10: 94-111.

13. Oren $Y$, Shapira $Y$, Agmon-Levin N, Kivity $S$, Zafrir Y, Altman A et al . Vitamin D Insufficiency In A Sunny Environment: A Demographic and Seasonal Analysis. Isr Med Assoc J 2010; 12: 751-56.

14. Mishal AA. Effects of Different Dress Styles on Vitamin D Levels in Healthy Young Jordanian Women. Osteoporosis Int 2011; 12: 931-35.

15. Gatenby P, Lucas R, Swaminathan A. Vitamin $D$ Deficiency and Risk for Rheumatic Diseases: an update. Curr Opin Rheumatol 2013; 25: 184-91.

16. Bouaddi I, Rostom S, Badri DE, Hassani A, Chkirate B, Abouqal R et al. "Vitamin D Concentrations and Disease Activity in Moroccan Children with Juvenile Idiopathic Arthritis", BMC Musculoskeletal disorder 2014; 15: 115 .
17. Hillman LS, Cassidy JT, Chanetsa F, Hewett JE, Higgins BJ \& Robertson JD. Percent true calcium absorption, mineral metabolism, and bone mass in children with arthritis: effect of supplementation with vitamin D3 and calcium. Arthritis Rheum 2008; 58: 3255-63.

18. Langman CB, Ford KK, Pachman LM, Glorieux $F$. Vitamin $D$ metabolism in rats with adjuvantinduced arthritis. J Bone Miner Res 1990; 5: 905-13.

19. Thacher TD, Clarke BL. Vitamin D insufficiency. Mayo ClinProc 2011; 86: 50-60.

20. Gordon CM, Feldman, HA, Sinclair, L, Williams, AL, Kleinman, PK, Perez-Rossello J, et al. Prevalence of vitamin $D$ deficiency among healthy infants and toddlers. Arch Pediatr Adolesc Med 2008; 162: 505-12.

21. Gordon CM, De Peter KC, Feldman HA, Grace E \& Emans SJ. Prevalence of vitamin D deficiency among healthy adolescents. Arch Pediatr Adolesc Med 2004; 158: 531-37.

22. Kumar J, Muntner P, Kaskel FJ, Hailpern SM \& Melamed ML. Prevalence and associations of 25-hydroxyvitamin D deficiency in US children: NHANES 2001-2004. Pediatrics 2009; 124: 362-70.

23. Maresova KB. Secondary osteoporosis in patients with Juvenile idiopathic arthritis. Journal of osteoporosis. 2011; 1-7. 